\title{
GRASSLAND MANAGEMENT FOR CLIMATE CHANGE ADAPTATION AND WATERSHED PROTECTION IN KARNALI WATERSHED AREA
}

\author{
Kabi Prasad Pokhrel
}

\begin{abstract}
Karnali watershed area is very sensitive and need of scientific management of highland grasslands which are rich in number of plants and animal species that have significant role and contribution in national economy and ecology. However, these grass lands are in threat and exist in their natural state within protected areas as neighboring grasslands and forest habitats have been rapidly degraded. At higher altitudes, trans-Himalayan and alpine rangelands are home to a diverse array of wildlife and are grazed by livestock, which are an integral part of the livelihood of several different ethnic groups. These grasslands are being overgrazed and little is known about the ecology and sustainability of prevailing land use practices at the community level. In this context, the prime concern of the paper is to address the existing issues, challenges along with biodiversity characteristics of the higher altitude grasslands of the region. Thus, the main focus of the paper is to point out the major issues of grasslands along with location specific as well as innovative measures and devises for the effective management of grassland beyond the protected and adjoin areas. Further, the paper explores some applicable measures to high land grassland management strategies with active participation of local communities with a view to provide comprehensive policy guidance for the sustainable management of grasslands in order to build the capacity of locals on the road to climate change adaptation and watershed protection in the Karnali region.
\end{abstract}

\section{INTRODUCTION}

Grasslands or pasturelands are the main source of forage for freeranging native and domestic animals as well as a source of wood products, water, energy, wildlife, minerals and recreational opportunities in Nepal which occupy 14 percent area of the country (MOF, 2012). In Karnali region, almost all communities rely on it to meet basic needs as well as to provide surplus for cash income and used in both native rangelands and forest grazing lands which cover around 10 percent of geographical area of the region (JAFTA, 2001; Pokhrel, 2011). Grasslands resources have been used for centuries in various purposes and managed as common property resources through complex institutional arrangements among pastoral groups, farm communities and social or governmental organizations. These vital resources are equally important for intangible products like natural beauty, open space, medicinal and aromatic plants, watershed conservation and eco-tourism that satisfy important social, cultural and economic values since long. The value and benefits from grasslands are gaining increasing recognition from the climate change adaptation point of

Dr. Pokhrel is an Associate Professor, Research Centre for Educational Innovation and Development, CERID, TU, Kirtipur, Nepal. 
view, particularly; these resources have significant contribution for carbon sequestration, watershed management, biodiversity conservation, integration of farmland, grasslands and forestland ecology, and support to continue traditional ecosystem services. However, these resources are rapidly becoming scarce resource. Many factors threaten and contributing to the decline due to converting land into individual tenureship as a process of conversion of pasturelands into farmland and its intensification. Most of the grasslands of the region are unsuitable for cultivation due to its physical limitations such as rouged topography, poor drainage, low precipitation and cold temperatures. Naturally, these grasslands are low in agricultural productivity and are often extremely variable in terms of climate and forage production. The marginal nature of pasturelands and adapted production system require to way out the sustainable management of grasslands in order to enhance the ecological productivity of grasslands, develop an extensive networks between grassland production systems with agricultural communities, and reduce risk associated with variable environment. It is important national task to enhance linkages between agricultural areas and extensive grasslands for interchange of products such as fodder, manure, milk, meat and food crops. Next aspect is to recognize pasturelands as viable land resources to implement the United Nations Framework Convention on Climate Change (UNFCCC) introduced mechanism of reducing emissions from deforestation and forest degradation (REDD+) in the regional context. The ever increasing trend of deforestation, resource degradation and habitat fragmentation affects rural resource based livelihoods and severe environmental threats are appearing nationwide. Experiences show that the proposed Nepal's REDD+ strategy can be implemented effectively by a great extent on watershed services and water resources, the rational given being in terms of upstream-downstream linkages to meet the goals of sustainable development, biodiversity conservation and improved livelihood for the poor. Climate change threats and challenges could be reduced and ensure the adaptation capacity by forest resources conservation and enhancement by addressing the livelihood concern of bioresource dependent people, and by establishing effective policy, regulatory, and institutional structures(Hussin,2011). Hunt (2009) pointed out an important way of adaptation of climate change to reduce carbon emission from land degradation and deforestation and said that one tone of carbon stored in grassland is the result of the removal of 3.67 tons of carbon dioxide from the atmosphere. It is estimated that forest ecosystems can absorb up to $3 \mathrm{Pg}$ of carbon(C) annually, however in recent years a significant portion of carbon has been returned to atmosphere through deforestation and degradation of grasslands. Further, grassland degradation leads to a decline of the natural resources e.i. decreased biodiversity, soil and water quality, rapid runoff, lower productivity, increased poverty, and vulnerability with land use pressure which directly effects to a significant reduction in soil carbon stock and plays important role in global warming. Pasture land or rangeland ecologists said that improved grassland and legume grass can fix required amount of carbon in soil and increase overall productivity of pasture land ecosystems (Ibrahim et al., 2007). But some cases, the large scale cultivation of simplified grass monocultures have found more vulnerable to climate change. From the above discussion It can be stated that the present policy 
focus needs to improve and link cropland, forestland and grassland ecosystems by applying bioengineering technique of multifunctional landscape as the process of mitigation of climate change adverse effects and harnessing of environmental benefits in terms of economic, ecological and social sustainability.

Global as well as regional revel research indicate that the well-managed grasslands in mountainous region in Nepal can effectively enhance over all biomass productivity, sequestering carbon potential economic benefit to the community people with multi strata live fences for recovering the traditional ecosystem services and also integrate pasture and agro forestry systems(Saenz et al., 2007; Mannetje et al., 2008). Grassland management and agro forestry integration could be one of the best strategies for poverty reduction, ecological restoration, enhancing agricultural productivity, carbon sequestration, and conservation of water, soil and other bioresource. This has multifold benefits such as farm production incensement at community level and benefits to world community and global environment. Scientific communities believe that the clean development mechanism (CDM) offered by Kyoto Protocol could reduce rural poverty by extending payments to low income farmers who provide carbon storage through sustainable land use system. Central American farmland- pasture land integration experience shows that both livestock productivity and environmental services are significantly increased by adoption of silvo-pastoral system (SPS) (Chagoya, 2004). Thus, the present paper tries to discourse the biophysical characteristics of high altitude grasslands of Karnali region with a view to dig out the need and importance of grassland management for mitigation of adverse effects of climate change and harnessing the environmental services to ecological, economical and social stability that could increase the farm level production and carbon stock in soil.

Grasslands have high inherent soil organic matter (SOM) content that supplies plant nutrients, increases soil aggregation, limits soil erosion, and also increases water holding capacities. Thus, maintenance of SOM is a key factor in the sustainability of grassland ecosystems. Soil organic matter in temperate grasslands averages $331 \mathrm{Mg} / \mathrm{ha}$, and grasslands contain 12\% of the earth's SOM. Grassland SOM can be strongly influenced by management. However, historical SOM losses can potentially be reversed, and atmospheric carbon (C) sequestered, with good agricultural management in Nepal where agricultural conservation practices such as reduced tillage, improved fertilizer management, elimination of bare fallowing, the use of perennials in rotations, and the use of cover crops can potentially sequester large amounts of atmospheric C. Similarly, areas converted from cultivation and maintained under well managed permanent grassland, as pastures or rangelands, constitute potential $\mathrm{C}$ sinks. Within established pastures, soil $\mathrm{C}$ can be increased by eliminating disturbances to the soil and by increasing primary production.

A variety of management techniques have evolved to increase forage production for livestock, which also have the potential to increase SOM. Improved management includes fertilization, irrigation, introduction of earthworms, intensive grazing management, and sowing of favorable forage grasses and legumes. As forage production increases, an ancillary benefit be increased sequestration of atmospheric carbon. Indeed, Gifford et al. (1992) noted 
that improved pasture management is an important consideration when computing the national $\mathrm{C}$ budget for Asia-Pacific region. Thus, the objective of this study is to examine the in- fluence of grassland management and conversion into grassland based on published data. to analyze the potential $\mathrm{C}$ sequestration following management improvement and following conversion of both native and cultivated lands to pasture land. Factors influencing $\mathrm{C}$ sequestration investigated across the region and through different forms of improved management. Finally, the study concentrated to e evaluate how time, sampling depth, and soil characteristics relate to sequestration rates of atmospheric $\mathrm{C}$, and how climate can influence management-induced changes in soil carbon.

\section{METHOD AND MATERIALS}

Data were compiled from the literature on the influence of grassland management and land use conversion to grassland on soil carbon. In order to make this study more useful for policy frame work for the watershed protection in the Karnali region,the study has examined land management system that has designed so that management was the primary factor influencing grassland management. A variety of management practices such as fertilization, intensity of grazing management, introduction of earthworms, introduction of legumes and grasses, and irrigation were taken to discuss. Management designated as improved if adoption generally resulted in increased forage production. For example, fertilization, irrigation, sowing legumes, and introduction of grasses or earthworms all considered management improvements. Grazing was designated as improved management if an ungrazed site appearent for comparison with grazed sites. Occasionally, a range of grazing treatments was compared without an ungrazed control. For these cases, the moderate stocking rate was considered improved management since low stocking rates may under utilize forage resources and high stocking rates may be abusive, both leading to decreased production. If more than one fertilizer treatment was evaluated within a study, each was compared with an unfertilized control plot. Land conversions from cultivation to perennial grassland were included in the analysis. Soil $\mathrm{C}$, information on latitude, longitude, soil texture, duration of treatment, mean annual temperature (MAT), mean annual precipitation (MAP), measurement techniques, experimental design, and primary production were recorded. Summary information about each data point is available. Studies included in this work generally used three different approaches to examine the influence of management of grassland soil carbon. Maintaining uniformity in comparison biodiversity characteristics land use and land management decisions have been studied. Data were often reported as percent status with no indication of the bulk density of the grasslandsl. Since data were standardized by calculating both the annual percent change following management improvement or conversion and the ratio of plant growth under improved grassland management with that under unimproved management.

\section{ECOSYSTEM SERVICES OF GRASSLAND}

The concept of ecosystem services is important for understanding human-environment relation and designing environmental policy intervention. Recently, payment for ecosystem services has emerged as policy solution for balancing goods (derived by individuals and services (derived by society) from natural systems. Experience with incentive-based approaches suggests that 
payment for ecosystem services (PES) of grassland can always be able to simultaneously improve livelihoods and increase ecosystem services, and that no single policy fits a range of scenarios in the Karnali region. To implement a successful PES strategy, the social, economic, and environmental contexts apparent as important factors in relation to determine the policy outcomes. Grasslands of Karnali watershed area provide important regulatory and buffering services to a large number of rural people; the provisioning services they provide are the backbone of the local economy. But these resources are influenced by policies in forests, agriculture, animal husbandry, land use, and rural development, the imposition of several policies and acts that are at times contradictory or overlapping found to be led to conflicts of tenure rights, unclear land records, faulty land use practices, and over exploitation grassland resources. With the growing importance linkage of farmland, grassland and forestland crucial ecosystem services and their potential role in mitigating climate change related impacts; future sect oral policies were reported by the local stakeholders in order to converge and focus to link and maintaining the integrity of these three land ecosystems so as to ensure the flow of goods and services.

The goods and services provided by the grassland ecosystems in the region are unique and varied by the geographical scale and location. Biophysical characteristics show their important contribution to upstream-downstream communities where both are seen similar beneficiaries of the ecosystem services. Main services provided by the Karnali watershed grassland ecosystem at are provisioning, regulating, cultural and supporting are given in table1.

Table: Grassland ecosystems services

\begin{tabular}{|l|l|l|l|}
\hline Provisioning services & \multicolumn{1}{|c|}{$\begin{array}{c}\text { Regulating } \\
\text { services }\end{array}$} & Cultural services & \multicolumn{1}{|c|}{$\begin{array}{c}\text { Supporting } \\
\text { services }\end{array}$} \\
\hline Food, Fuel, Forage & $\begin{array}{l}\text { Climate } \\
\text { regulation }\end{array}$ & $\begin{array}{l}\text { Local, historical } \\
\text { and religious }\end{array}$ & Nutrient cycling \\
\hline $\begin{array}{l}\text { Derivatives of Farm } \\
\text { and Livestock } \\
\text { products }\end{array}$ & $\begin{array}{l}\text { Water cycle } \\
\text { regulation }\end{array}$ & Recreational & $\begin{array}{l}\text { Interlink between } \\
\text { socio-ecological } \\
\text { system }\end{array}$ \\
\hline $\begin{array}{l}\text { forest products } \\
\text { (TFP,NTFP \& MAPs) }\end{array}$ & $\begin{array}{l}\text { Flood and land } \\
\text { slide mitigation }\end{array}$ & Aesthetic & $\begin{array}{l}\text { Food chain and } \\
\text { food web maintain }\end{array}$ \\
\hline $\begin{array}{l}\text { Fuel wood and } \\
\text { Greenery }\end{array}$ & $\begin{array}{l}\text { Ecological } \\
\text { balance }\end{array}$ & Ethical & $\begin{array}{l}\text { Continuing } \\
\text { traditional life } \\
\text { support services }\end{array}$ \\
\hline Fresh water & $\begin{array}{l}\text { Carbon } \\
\text { sequestration }\end{array}$ & Educational & Water cycling \\
\hline Fresh air & GHG reduction & Symbolic & $\begin{array}{l}\text { Enhancing } \\
\text { livelihood }\end{array}$ \\
\hline
\end{tabular}

Source: Adopted and modified from ICIMOD, 2013.

It is evident from the table-1 that the provisioning services of the ecosystem services are the most crucial for the wellbeing and survival of the local communities those who depend on the rural natural resources. Forest products, farm products and livestock products benefit communities at both local and regional scales. The benefits provided by the grasslands ecosystem of climate control, water regulation, flood and landslide mitigation soil erosion control and 
carbon sequestration occur at a large scale and benefit upstream-downstream communities in the area.

\section{BIOPHYSICAL CHARACTERISTICS OF GRASSLAND}

Grasslands are generally composed by a mixture of grasses, broad-leaved flowering plants, bushes, herbals, meadows and free from tall trees. They develop in area with $25-75 \mathrm{~cm}$ of annual rainfall and cool and cold temperatures. Plant species found in high altitude grasslands in the region are grasses, glasslike sedges, bushes forbs, and meadows which known as forage medicinal herbs and shrubs and supply food and energy for domestic and wildlife animals. Some of them graze on grasslands and some others browse on leaves, twinges and shoots. A leaf tip of grassland vegetation like is nibbled off without affecting growth as long as the lower most portion of the leaf remains intact and in a short span of time the leaf can grow to its original length. So that grass leaf can be grazed again and again without any adverse effects, as long as the plant has some time to recover. Thus, in biological characteristics these grass species have provided continuous food reservoir for the grazing animals in high altitude area in the region. Grassland ecologists viewed that the upper 50 per cent of the grass shoot (stem and leaves) as a surplus that can be safely eaten by herbivores without damaging the plants. The rest lower 50 per cent known as the metabolic reserve i.e. necessary for grass survival (Owen, et al., 1998). This portion provides required amount of photosynthesis that needs to manufacture foods for the roots. The seasonal growth of available grass species in Karnali region have been presented in fig-1.



Fig-1: Grass Growth Rate

Available grassland species in the area are to be classified into three categories with respect to the dynamics of plant succession.

(i) Decreases are highly nutritious; extremely palatable that generally decreases under grazing pressure and extracting of aromatic and 
medicinal herbs by uncontrolled human activities. These species are big bluestem, little bluestem, blue gram, wheat grass and others.

(ii) Increasers are less palatable but highly nutritious climax species that tend to increase with heavily grazed. It is due to the result of reduced competition from the decreases. Severe grazing pressures over a long period the increasers being to decline and replaced by invaders.

(iii) Invaders are undesirable weeds with low nutritional value and not suitable for grazing. Some are poisonous also. These species have shared seeds that can harm animals by lodging in their throats or piercing their skin. Invaders are not also effective and useful in binding the soil by their taproots.

\section{Challenges AND ISSUES OF GRASSLAND ECOLOGY}

An excellent condition of grassland has to contain by high percentage of degreasers almost no invaders from the view point of ecological balance of grassland. However, in recent years the grassland ecology of the Karnali watershed area is being poor by the gradual decline of palatable and highly nutritious forage-value decreasers and an increasing proportion of low forage invaders. Consequently, the carrying capacity of the grassland ecology of the area is to decline and loss the grazing capacity of maximum number of herbivores biomass that grazes each year without causing downward trend in forage production, forage quality and soil quality. The declining trend of carrying capacity of high altitude grassland is affected by various factors like annual climatic conditions, grassland use practice, kinds of grazing animals and duration of grazing and herbal harvesting. There is also an increasing trend to converse that grassland and other marginal lends into farmland and local communities found to move to extent their agricultural land as the main cause to decline the quality and quantity of grassland in the Karnali region. Another vital cause to decline grassland quality in the area is low level of peoples' participation on common property resources management. It is widely observed that local people are very active to use common resources like grasslands and forestlands for their personal or household benefits but nobodies takes care to manage common resources like watersheds, water sources, grasslands and other such resources which have much more intangible value for the regions' healthy environment and rich biodiversity. Government role in terms of policy and program in favor to conservation and management of grassland in the Karnali watershed area is not also effective because of the local government authorities are not serious to implement the grassland eco-friendly development activities and also not found any such programs that increase the public awareness on grassland conservation, management and sustainable utilization at the community level. All this creates the current state of grassland ecology which is in challenging by lowering the potential natural as well as ecological quality and has no any specific action plan in the area. Till now, Forest Department is a single responsible government authority to mobilize all national resources and policies for the proper management of grasslands. But in practice, Forest Department has given less priority to the grassland management and high emphasis has been given to forest. Therefore, grasslands in the Karnali 
watershed are severely abused, misused and overused due to improper grazing system, week government policy and low level of public awareness on common resource like grassland management sustainably. Similarly, limited data from partial survey on grassland management and utilization show the grasslands have been rapidly degraded in the area. Very few technical assessment made in past by governmental and non-governmental organizations show that the regions' overgrazing trends had led large amount of soil erosion and more than 60 percent grasslands have been losing productivity. An example of summer grass seen has been given in fig-2

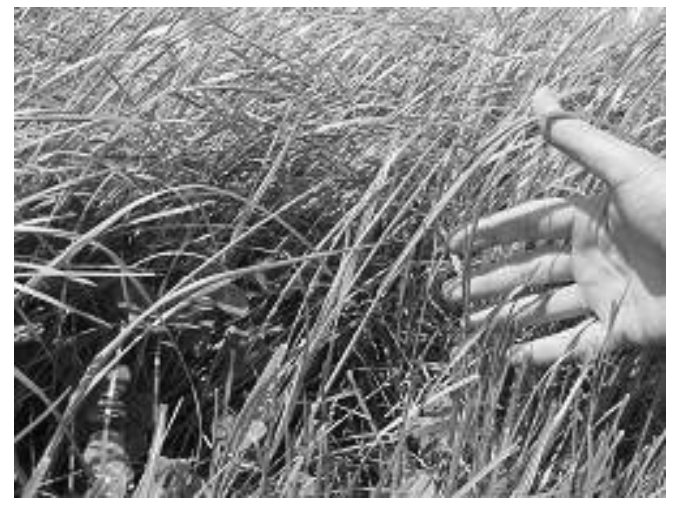

Fig-2: Summer Grassland Scene

This trend will continue to do so unless sustainable management practices are put in action-place (Ives and Messerli, 1996). A case study made by Pokhrel (2011) stated that grassland carrying capacity of the Karnali watershed has been declined by 50-80 per cent and some where desertification process has appeared. Almost all grasslands are experiencing overgrazing and over harvesting of herbal plant species and decreased forage production grass. Particularly, grassland area of Jumla and Kalikot show signs of a rapidly deteriorating forage production and approaching towards desertification. Grassland in Dolpa has also serious overharvesting problem where the carrying capacity of grassland is far exceeded by Yarshagumba collectors. YARSAGUMBA is Nepalese Tibetan name dbyar rtswa $d g u n ' b u$ (summer grass, winter worm) for a rare fungus that parasites on the body of a caterpillar of a moth (genus THITARODES). This so-called CATERPILLAR FUNGUS (CORDYCEPS, or also OPHIOCORDYCEPS SINENSIS) grows only at high altitudes. For its medical effects, YARSAGUMBA has been an important component for a many of years in Traditional Chinese Medicine. However, due to a constantly growing demand and the difficulties in harvesting, YARSAGUMBA has become the most expansive medicinal substance in the world (Fig-3). 


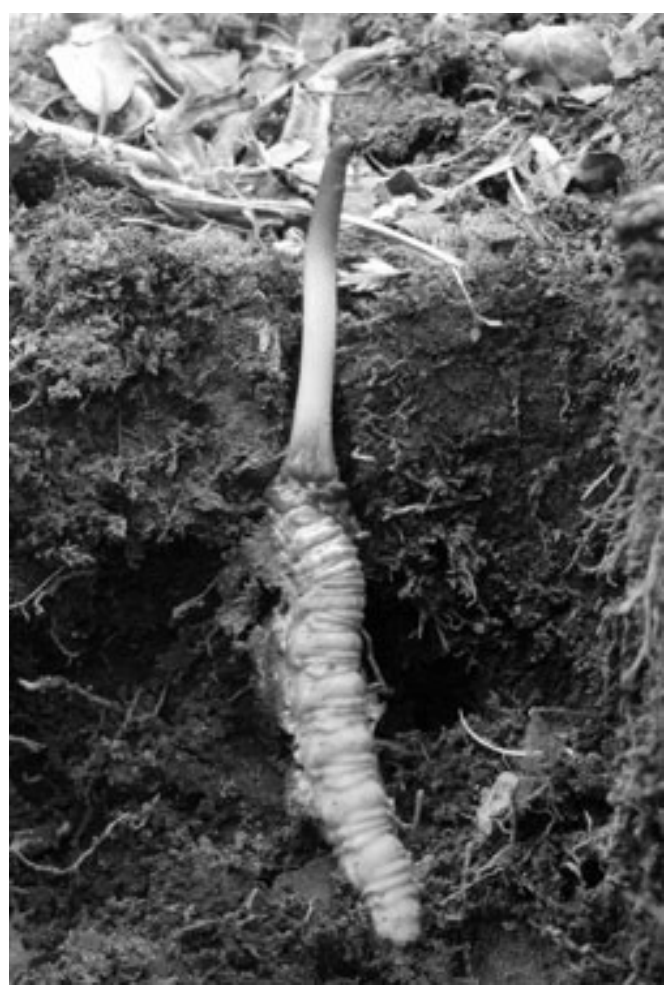

Fig-3: Sample of Yarsagumba found in Pasture/grassland in Karnali Watershed Area

The caterpillar of a moth genus THITARODES (Hepialus) lives underground in alpine grass and shrub lands at an altitude of $3000-5000 \mathrm{~m}$ spending up to 5 years underground before pupating, feeding on roots of a plants. During this larvae state, the caterpillar is attacked by a fungus of the genus OPHIOCORDYCIPITACEAE. It is not certain how the fungus infects the caterpillar - possibly by ingestion of a fungal spore or by the fungus mycelium, invading the insect through its breathing pores. The fungus fills its entire body cavity with mycelium, eventually killing and mummifying the insect. Before this happens, somehow, the fungus causes the caterpillar to get near the top of its burrow. In springtime, after the snow melts, mushrooms emerge from the ground, always growing out of forehead of the caterpillar. The size of a mature mushroom reaches $5-15 \mathrm{~cm}$ above the surface and releases its spores onto the ground, and the cycle repeats in the high pasturelands especially in Karnali region. But recently, this valuable medicinal species in the threat to extinction by the thousands of Yarsagumba collectors go in search of during the spring season. The returns are worth the effort and the risks involved since a person can earn over 2,500 dollars in a good season (a tidy sum considering that the annual per capita of Nepal is below 500 dollars). Usable upper of Yarsagumba needs only be used in sustainable way in order to continue its production by the proper management of highland grassland in the region (fig-4). 


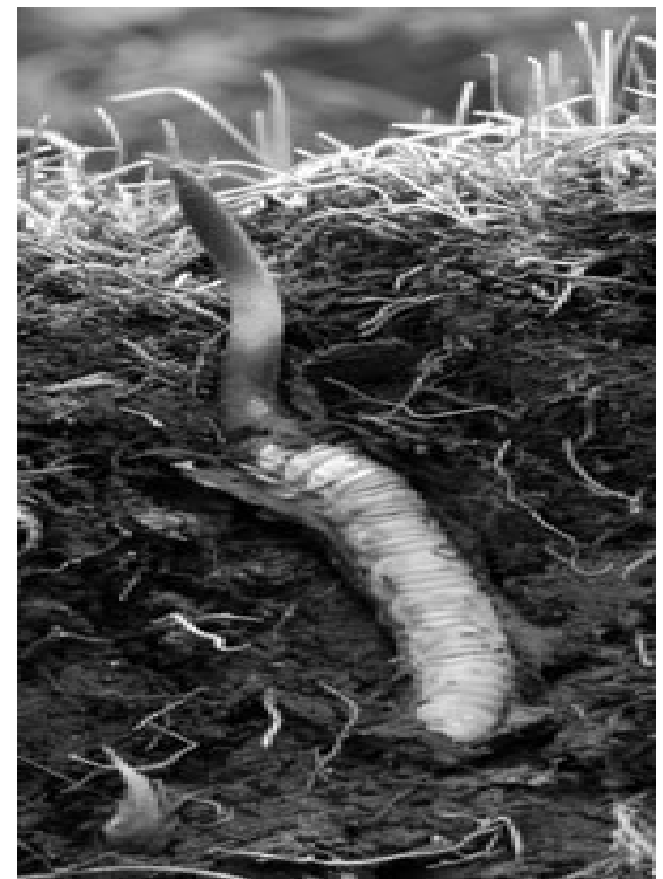

Fig-4: Usable Upper part of Yarsagumba

Yarasagumba has been a part of traditional Chinese medicine since ancient times. Its many attributes have been studied at some length by some scholars, particularly Chinese scholars who recommend Yarsagumba for the treatment of stress and fatigue, for respiratory diseases like tuberculosis and asthma, for disease related to the kidneys and the liver, as well as for cardiovascular distresses, and so on. However, the one use of Yarsagumba that has caught most of the world's attention is its use as an aphrodisiac. Tibetan medicine lists Yrasagumba as a tonic for boosting immunity and for enhancing virility aside from its supplementary role along with other medicines in kidney, lungs and heart problems. Yarsagumba is also recommended by Tibetan traditional practitioners for improving eyesight and for treating Hepatitis B.

It is evident that pastureland is an important natural resource of the Karnali watershed area from the point view of economic growth, livelihood improvement, public health promotion and ecological soundness. In overall more than 60 per cent of population of Karnali region are directly or indirectly dependent on regions' grassland resource which has severely degraded in since the last decades.

\section{Grassland Management: NeEd and Practice}

Foregoing discussion permits to say that the life species and ecosystems of grassland are seriously threatened in Karnali region which are the prime of biological resources that are vital to regions' ecology and economy as well as for the national prosperity. But both political and 
economic systems fail to build sustainable linkage between grassland ecology and livelihood of the community people. It is true that the struggle to save species and ecosystems cannot be divorced from the broader struggle to achieve a new world order in which the basic needs of all are met. Scientific communities and even affected communities realized that the sustainable production of food, fuel, fodder, medicines and water in rural areas depends on ecosystem services derived from adjacent three land ecosystem (cropland, grassland and forestland) services and their interrelation. Thus, focus has to be integrated the three land ecosystem with a view to enhance the biological productivity and continuity of traditional ecosystem services in which all life species including human feel comfort and easy to grow, development and extension. Various methods, approaches and action-strategies have been practiced for the sustainable management of grassland at global scale; however, the replicable results are varied according to local geography, technology and impressive output of the action in relation to point out the role for harnessing environmental services. Biodiversity of the region clearly shows that there is an urgent need to develop a land use change biodiversity index for each change and to analyze the relationship between carbon sequestration and biodiversity for addressing multiple issues that facing by the region. From the sustainable point of view watershed management and conservation methods are more economical and environmental sound ways to prevent the natural hazards, mitigate the rising climatic problems and to enhance the ecological productivity in terms of harnessing soil fertility, water storage capacity, aquifer recharge, wildlife habitat and agriculture. Therefore, sound farming and forestry practices are to be best path ways for the protection of grassland in the region by applying watershed management approach. This approach especially preserves the natural water storage capacity and aquifer recharge zones that enhance river fed by grassspecies and ultimately control the soil erosion, carbon sequestration and biodiversity conservation through active participation of local communities.

The main goal of grassland management is to maximize the livestock or herbivore productivity without degrading grassland quality. Thus, grassland management is an interdisciplinary field of task that uses inputs from soil and plant sciences, geomorphology and climatology, animal and wildlife sciences, forestry, hydrology, political economics and other related applied disciplines for the proper understanding of grassland ecosystem services so that past changes can be explained and future influence predicted. The best strategy of grassland management in the Karnali region is to prevent grassland from deteriorating and measures have to be applied for determining the carrying capacity of grassland ecosystems that help to avoid overgrazing as well as uncontrolled herbal harvesting, practicing stock manipulation and artificial seeding. Managers, policy makers and ranchers need to understand that animals tend to concentrate in meadows and along stream margins and to avoid ridges and slopes. So, proper management of grassland has to focus to locate water holes and salt blocks. Because cattle and other herbivores normally congregate around water sources so that salt blocks need to be placed roughly 0.8 kilometer from the nearest water source, preferably in 
ungrazed areas on ridges, sloppy area where livestock normally avoid to graze. Sustainable grassland management community initiations and policy efforts would enhance the productivity of bio resources in the region. It would help to improve the commercial livestock farming and production of medicinal species. There is high potentiality to promote the commercial livestock farming for the sustainable livelihood improvement of the inhabitant of the Karnali region. The perspective of the scientific grassland management in the region is too high as given in fig-5.

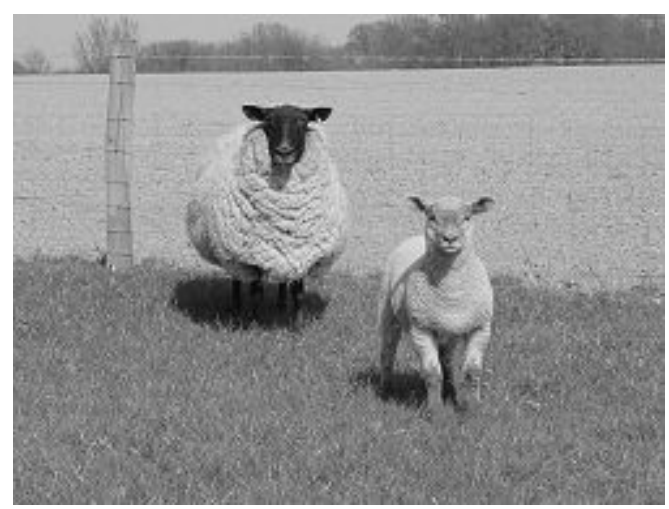

Fig-5: Perspective of sheep farming in Karnali Region

\section{CONCLUSION}

Grassland management concerns the production and utilization of grass. In the region the formal management of grassland can be traced back to the past over 100 years ago as farmers sought to convert grass into useful products, for example milk and meat. It considers highland grassland management in the context of present ecology and farming life in the region. Amongst the many different types of grass that are found throughout the Karnali region, all share a common characteristic in their seasonality of growth. Grass hardly grows at all when the temperature is below $0^{\circ} \mathrm{C}$, but grows vigorously in the warm wet conditions that are typical of the April, May and June period. The productive capacity of grassland in the region seen to depend on a large number of factors but in the main is dependent upon the climate and the soil. Mild temperate weather with deep rich soils being the most favorable. Other factors such as the topography of the land, species mix, and sward damage can be important, but generally to a lesser extent. Grass, like all other crops, responds to soil conditions that are high in fertility. This may be naturally occurring or it can be artificially enhanced by the application of fertilizer. The principal nutrients that grasslands require in the region are nitrogen $(\mathrm{N})$, phosphorous $(\mathrm{P})$, potash (K) and sulphur (S) where the (letter) symbolizes the appropriate element. Farmers can apply fertilizer in either organic or inorganic form, depending upon its availability and suitability.

The challenge for grassland management is to exploit the potential of grass growth in the early summer period by growing lots of it, but in such a 
manner that it is utilized without waste. This necessitates part of the grassland area being allocated for the production of silage or hay for use as a winter fodder. Surplus grass growth in relation to livestock requirements is illustrated in the graph alongside. In the spring local people may be reserving as much as $2 / 3$ of their grassland acreage for the production of silage or hay. By midsummer this may have fallen to $1 / 3$ with the entire grassland acreage being grazed by late summer. However, grassland management is about more than just production. It needs to conserve grass (silage and hay) that is of the right palatability and nutritional quality. In this respect commercial livestock farming needs lots of young nutritious grass or silage to support milk production whereas cattle do best on grass that is more mature and of lower palatability. Sheep require swards where the grass length is short and will not utilize grassland efficiently if the grass is more than a few inches tall. The effective management and utilization of grassland therefore often involves different livestock grazing the same grassland in a complimentary manner. The case of sulphur is interesting to be discharged into the atmosphere in large quantities by process that gave rise to acid rain. Although acid rain was detrimental to some ecosystems it nonetheless provided necessary sulphur to grassland and arable crops. With the advent of much cleaner burning technology and a move towards cleaner fuels (solar energy instead of fuel wood), the amount of sulphur in the atmosphere has greatly reduced and grass can become deficient without additional application by the local people.

\section{WORKS CITED}

Chagoya, J. (2004). Investment analysis of incorporating timber trees in livestock farm in the sub-humid tropics of Costa Rica. CATIE, Turrialba.

Hunt, CAG (2009). Carbon sinks and climate change: forests in the fight against global warming: e-book. Cheltenham, Edward Elgar UK.

Hussian,Y.A. (2011). "Mapping carbon stocks in community forests of Nepal using high spatial resolution satellite images." Sustainable Mountain Development, ICIMOD. 60: 22-24.

Ives, J.D. and Messerli, B. (1996).The Himalayan dilemma: reconciling development and conservation.: Routledge, London and New York.

Imbrahim, M., Chacon, M., Curtas, C., Naranjo, J., Ponce,g.,VgaP.,Casasola, F. and Rojas, J. (2007). Almacenamiento de carbono en el suelo yla biomasa aerea en sistemas de uso de la tierra en paisajes ganderos de Cplombia, costo Rica y Nicaragua. Agroforesteria en las Americas. 45: 26-37.

Japan Forest Technology Association (JAFTA). (2001). Activity report of wide area tropical forest resources survey, Kingdom of Nepal. Information System Development Project, Kathmandu.

Mannetje,L., Amezquita, M.C., Buurman, P. and Ibrahim, M. (2008). Carbon sequestration in tropical grassland ecosystems. Wageningen. Wageningen Academic Publishers, Netherlands. 
Owen,O.S.; Chiras,D.D.and Reganold,J.P.(1998). Natural resource conservation: management for a sustainable future.7th ed., PRENTICE HALL, New Jersey.

Pokhrel, K.P. (2011). Resource development (land, water and forest) in Nepal: an inquiry of Mid Western Region. Kathmandu: Acme Global Publication Pvt. Ltd.

Saenz, J.C., Villatoro, F., Imbrahim, M., Fajardo, D., and Perez, M. (2007). Relacion entire las communidades de aves y la vegetacion en agropaisajes dominados por la ganaderia en Costa Rica, Nicaragua Colombia. Agroforesteria en las Americas, 45: 3-48. 